OPEN ACCESS

Edited by:

Xi Zhang,

Shenzhen University, China

Reviewed by:

Siddharth Surajbhan Gautam,

The Ohio State University,

United States

Jean-Marc Simon,

Université de Bourgogne, France

*Correspondence:

Yuan-Mei Song

songyuanmei@lyu.edu.cn

Specialty section:

This article was submitted to

Physical Chemistry and Chemical

Physics,

a section of the journa

Frontiers in Chemistry

Received: 16 February 2020

Accepted: 04 May 2020

Published: 16 June 2020

Citation:

Song $Y-M$, Liang $R-Q$, Wang $F$ Shi J-H, Zhang $D-B$ and Yang $L$ (2020) Enhancement of Clathrate Hydrate Formation Kinetics Using Carbon-Based Material Promotion.

Front. Chem. 8:464.

doi: 10.3389/fchem.2020.00464

\section{Enhancement of Clathrate Hydrate Formation Kinetics Using Carbon-Based Material Promotion}

\author{
Yuan-Mei Song ${ }^{1 *}$, Ru-Quan Liang ${ }^{1}$, Fei Wang ${ }^{2}$, Jian-Hui Shi ${ }^{1}$, Deng-Bo Zhang ${ }^{1}$ and \\ Liu Yang ${ }^{1}$ \\ ${ }^{1}$ The School of Mechanical \& Vehicle Engineering, Linyi University, Linyi, China, ${ }^{2}$ Shandong Engineering Laboratory for \\ Preparation and Application of High-Performance Carbon-Materials, College of Electromechanical Engineering, Qingdao \\ University of Science \& Technology, Qingdao, China
}

Although hydrate-based technology has been considered as a safe and environmentally friendly approach for gas storage and transportation in recent decades, there are still inherent problems during hydrate production, such as a long induction time, slow formation kinetics, and limited hydrate storage capacity. Attempts to resolve these issues have resulted in the development of various kinetics promoters, among which carbon-based materials have become one of the most attractive owing to their unique promotion effect. Herein, results on promotion by bulk wetted carbon materials in the forms of a packed bed, carbon particles in a suspension, and nano-carbon materials in a nanofluid are collected from the published literature. Meanwhile, the promotion mechanisms and influencing factors of the carbon-based promoters are discussed. The purpose of this mini-review is to summarize recent advances and highlight the prospects and future challenges for the use of carbon-based materials in hydrate production.

Keywords: gas hydrates, methane storage, efficient promoter, carbon-based materials, kinetic promotion

\section{INTRODUCTION}

Natural gas hydrate, also referring to the methane hydrate, is an ice-like clathrate constituted by hydrogen-bonded water molecules and light molecules like methane that have filled in the cavities via Van der Waals force (Sloan, 1998). This solidified natural gas (SNG) has been viewed as a potential alternative for natural gas transportation and storage because of several advantages (Thomas, 2003; Javanmardi et al., 2005; Koh et al., 2011; Veluswamy et al., 2018): the high volumetric storage capacity of $160-180 \mathrm{v} / \mathrm{v}$, much milder formation and storing conditions than CNG and LNG, e.g., at $273.15 \mathrm{~K}$ and 3.2 MPa for methane hydrate formation, and safe and environmentally benign manufacturing process. However, technical challenges arise in the production process, primarily the slow kinetics of hydrate formation, large amount of heat generated, and limited gas storage capacity. Hydrate formation is always accompanied by heat release, which will impede hydrate growth if the heat is not removed in time, particularly in large-scale industrialization. Moreover, the theoretical gas storage capacity is hard to achieve due to the retarded mass transfer caused by the formation of thin hydrate layers at gas-liquid interfaces (Lee et al., 2006; Aman and Koh, 2016). 
A great deal of effort has been focused on developing efficient methods for overcoming the above issues. To date, the most well-studied field is the formation of methane hydrates in the presence of surfactant, among which sodium dodecyl sulfate (SDS) showed the best performance (Zhong and Rogers, 2000; Kumar et al., 2015). In a recent review article, $\mathrm{He}$ et al. He et al. (2019) have provided a good review of surfactantpromoted gas hydrate formation during the past three decades. Given the enormous amount of foam production in hydrate dissociation and the difficulty of recycling the surfactant, nonsurfactant-based methods for improving hydrate formation have attracted growing attention over the last 10 years. A review by Veluswamy et al. (2018) documented and discussed in detail the different materials applied for methane hydrate formation, e.g., silica gel, dry water, dry gel, sand, zeolite, and hollow silica, which are used as a fixed bed for hydrate reaction. Another review conducted by Nashed et al. (2018) shed light on the nanomaterials for gas hydrate formation, where various metal-based particles, like nano- $\mathrm{Ag}, \mathrm{Cu}, \mathrm{CuO}$, and $\mathrm{ZnO}$ were discussed, and it was concluded that nanoparticles not only could help to promote mass transfer but they could also contribute to heat transfer enhancement in the hydrate reaction. Additionally, some non-metal materials such as silica nanoparticles (Wang et al., 2019), graphene (Wang et al., 2017), and carbon nanotubes (Pasieka et al., 2014) exhibited excellent performance in promoting gas storage capacities and hydrate formation rate.

As carbon-based materials (e.g., activated carbon, graphite, graphene, and carbon nanotubes) have been widely employed in gas hydrate formation in recent years, this mini-review summarizes the published studies where the promotion effects of carbon-based materials on gas hydrate formation were investigated. With an attempt to draw critical conclusions after compiling this knowledge into a single article, this review provides significant guidance for developing novel methods for hydrate-based technology.

\section{GAS HYDRATE FORMATION WITH CARBON-BASED MATERIALS}

Porous carbon-based materials, such as active carbon, graphite, carbon nanotubes, and graphene, can realize gas adsorption due to their porosity and high specific areas when utilized for hydrogen or methane storage (Nikitin et al., 2008; Mohan et al., 2019). During research on the gas adsorption process, scientists discovered that when carbon materials were wetted by water or dispersed in water, a higher methane storage capacity was obtained via hydrate formation under certain conditions. Hence, carbon materials attracted research interest as efficient promoters for the gas hydrate formation, resulting in numerous investigations in the last 10 years. Referring to the literature concerning different kinds of carbon materials, this section is divided into three parts: the promotion of gas hydrate formation by bulk carbon materials, carbon-based suspensions, and carbon-based nanofluid, respectively.

\section{Gas Hydrate Formation With Bulk Carbon Materials}

Since natural gas hydrates are usually stored within porous sediments in nature, it is essential to understand the characteristics of hydrate formation in porous space. In experiments, the reactor is often filled with bulk materials with adsorbed water in the form of a packed bed for hydrate formation. The mass ratio of water to bulk materials, the material types, and the pore size are the primary factors that affect the gas hydrate formation rate and storage capacity.

The literature regarding the use of porous carbon materials (mainly referring to activated carbon) in methane hydrate formation is listed in chronological order in Table 1A. The porous material first reported as being for hydrate formation was active carbon, in an investigation by Zhou and Sun (2001). They found that wet activated carbon caused an increase in methane adsorption isotherms and enhanced gas uptake by $60 \%$ at a water ratio of 1.4 . Later on, many studies proved the optimal water/carbon mass ratio to be about 1 (Perrin et al., 2003; Yan et al., 2005; Celzard and Marêché, 2006). By analysis of pore styles, Perrin et al. found that microporosity seemed to be useless for clathrate formation, while mesoporous and macroporous carbon materials were more favorable to enhancing hydrate formation. Following this work, Celzard and Marêché (2006) proved, however, that saturated pore space would slow down the hydrate formation kinetics since gas diffusion pathways became scarce when the small spaces in the pore network were filled by water. Similarly, another study showed that a $96.5 \%$ enhancement of water conversion was obtained due to the larger interstitial pore space between activated particles than between other smaller particles under $8 \mathrm{MPa}$ and $4^{\circ} \mathrm{C}$ (Siangsai et al., 2015). Via observation of the morphology of methane hydrate formed in porous media of activated carbon, Babu et al. (2013) confirmed that the hydrates primarily nucleated on the surface of the activated carbon and that whether the hydrates further developed into stable hydrate crystals depended on the interstitial space between the activated carbon particles. As a consequence, porous activated carbons with an optimal water ratio can provide excellent interfaces that enlarge the area of gas-liquid contact for hydrate nucleation and growth, and the hydrate formation process is only accelerated by active carbons with large pore size rather than micropores.

Aiming to determine the critical hydrate formation conditions, phase equilibrium estimations of gas hydrate formation in porous carbon materials have been conducted in many experimental or theoretical studies. The methane hydrate equilibrium was usually shifted to a higher pressure or lower temperature in bulk carbons compared to pure water (Najibi et al., 2008; Mingjun et al., 2010; Yang et al., 2012). For example, Liu et al. (2018) measured the methane hydrate formation or dissociation conditions in eleven porous materials, verifying that smaller pores size (below $6.2 \mathrm{~nm}$ ) exerted a negative influence on the hydrate formation conditions due to extra capillary pressure in these pores. Taking the pore size, pore distribution, capillary pressure, and hydrate-liquid interfacial tension into consideration, some new equilibrium models were established 
TABLE 1 | List of the carbon-based materials used in methane hydrate formation.

\begin{tabular}{|c|c|c|c|c|c|c|}
\hline Carbon material & $\begin{array}{l}\text { Pore size } \\
\text { (nm) }\end{array}$ & $\operatorname{SSA}\left(\mathrm{m}^{2} / \mathrm{g}\right)$ & $\mathbf{R}_{\mathrm{w}}$ & $\mathbf{T}(\mathbf{K})$ & $\mathbf{P}$ (MPa) & References \\
\hline \multicolumn{7}{|c|}{ (A)-FOR BULK CARBON-BASED MATERIALS } \\
\hline Activated carbon & - & 1,800 & 1.4 & 275 & 4.6 & Zhou and Sun, 2001 \\
\hline NC58 & - & 1,000 & 1.0 & 275.15 & 8 & Perrin et al., 2003 \\
\hline NC86 & & 1,257 & & & & \\
\hline NC120 & & 2,031 & & & & \\
\hline Picazine & & 1,967 & & & & \\
\hline Activated carbon & 1.9 & $\begin{array}{c}978 \\
1,126\end{array}$ & $\begin{array}{l}1.7 \\
2.9\end{array}$ & 278 & 8 & Yan et al., 2005 \\
\hline Activated carbon & - & $\begin{array}{l}1,000 \\
1,587 \\
2,031\end{array}$ & $\begin{array}{l}1.09 \\
0.72 \\
0.85\end{array}$ & 275.15 & 8 & Celzard and Marêché, 2006 \\
\hline NC120 & - & 2031 & 1.0 & 277.15 & 10 & Najibi et al., 2008 \\
\hline Picazine & & 1967 & & & & \\
\hline Activated carbon & 2.19 & 866.7 & $\begin{array}{l}0.5 \\
1.0\end{array}$ & 277.15 & 8 & Babu et al., 2013 \\
\hline Activated carbon & - & $864-918$ & 1.0 & 277.15 & 6 or 8 & Siangsai et al., 2015 \\
\hline Activated carbon & 1.5 & - & 0.3 & - & 10 & Liu et al., 2018 \\
\hline Particles & Concentration & $\mathbf{T}(\mathbf{K})$ & $\mathbf{P}$ (MPa) & $\begin{array}{l}\text { Duration } \\
\text { (min) }\end{array}$ & $\begin{array}{c}\text { Storage efficiency } \\
\text { improvement }\end{array}$ & References \\
\hline \multicolumn{7}{|c|}{ (B) FOR CARBON NANOTUBE-BASED NANOFLUID } \\
\hline OCNTS & $0.001-0.006 \%$ & 274.15 & $3 \& 4$ & 720 & $375 \%$ & Park et al., 2012 \\
\hline OCNTS & $0.001-0.006 \%$ & 274.15 & - & 720 & $260 \%$ & Pasieka et al., 2013 \\
\hline OCNTS & $1 \times 10^{-6}-1 \times 10^{-4} \%$ & 275.15 & 4.7 & - & - & Lim et al., 2014 \\
\hline $\begin{array}{l}\text { SDS@ } \\
\text { CNTs }\end{array}$ & $0.05-0.6 \mathrm{mg} / \mathrm{L}$ & 275.15 & 6 & 100 & $600 \%$ & Song Y. et al., 2017 \\
\hline RR195@CNTs & 2-40 ppm & 275.15 & 6 & 203 & $250 \%$ & Song et al., 2019 \\
\hline $\mathrm{f}-\mathrm{CNTS}$ & 10-150 ppm & 275.15 & 6 & 100 & $575 \%$ & Song Y. M. et al., 2017 \\
\hline $\begin{array}{l}\text { Ag@ } \\
\text { OCNTs }\end{array}$ & 20 ppm & 275.15 & 6 & 110 & $650 \%$ & Song et al., 2018 \\
\hline
\end{tabular}

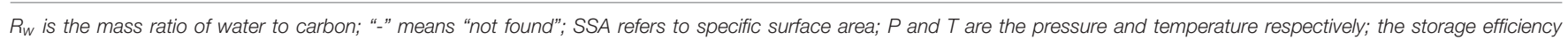
improvement was calculated based on a pure water system.

and also supported the experimental results (Zhang et al., 2020).

The addition of a traditional promoter such as a surfactant or thermodynamic promoter into the water or offering hydrophobic/hydrophilic groups on the carbon surface have proved to be efficient ways of improving gas storage capacity and the hydrate formation rate in porous media (Casco et al., 2017; Cuadrado-Collados et al., 2020; Palodkar and Jana, 2020; Zhang et al., 2020). In the latest research, Cuadrado-Collados et al. (2020) reported the promotion effects of various additives, such as the sodium dodecyl sulfate (SDS), leucine, and tetrahydrofuran (THF) in the confined nanospace of the carbon surface, where hydrate nucleation and growth rate were both accelerated significantly. A similar work was conducted by Zhang et al. (2020), who noted that, when anionic active groups aggregated onto the surface of the porous media, the modified carbon could promote gas adsorption and enhance formation process because of micellar solubilization in the presence of SDS. By introducing oxygen-containing groups on the activated carbon, the carbons performed better after being wetted by water, as shown by the result that the methane hydrate yield was elevated to $51 \%$ for oxidation-treated carbons under the conditions of $3.3 \mathrm{MPa}$ and $2^{\circ} \mathrm{C}$. It was assumed that the locations of the oxygen groups on the surfaces of carbons acted as nucleation centers for water clustering, which benefited further hydrate growth (Casco et al., 2017). Herein, after functionalization or being attached to other promoters, porous carbon materials provided more efficient reaction media for hydrate formation.

There are two basic kinds of promotion mechanism for hydrate formation in wetted porous carbon materials. The generally accepted mechanism is the interface adsorption theory (Zhou and Sun, 2001; Mingjun et al., 2010; Cuadrado-Collados et al., 2018; Andres-Garcia et al., 2019). Unlike in the gas-free water system, there are many voids among and inside the carbon particles when water is absorbed in porous activated carbon, and these will provide efficient contact areas for gas and water. The hydrate formation process can then be described as: liquid water films gradually form at the surface of the carbon interface, followed by hydrate formation after gas adsorption at the water-carbon interface. This theory also points out that methane 
hydrates tend to form in wider pores and the intersectional spaces between particles. Another promotion mechanism is the capillary effect caused by the pores or interstitial space in the porous media. As the capillary force can enhance liquid phase migration in the pores, continuous gas-liquid contact is realized, and hydrate formation distributions are changed constantly. This promotion mechanism became more obvious when surfactant was added to the porous materials (Zhang et al., 2020). However, in this light, a minimum pore size of about $3 \mathrm{~nm}$ is required for methane hydrate formation considering the hydrate crystal size. Conversely, in some cases, the pore capillary force was assumed to reduce the activity of the pore-confined water that hindered hydrate formation (Liu et al., 2018).

\section{Gas Hydrate Formation With Carbon-Based Suspensions}

Suspensions formed by carbon particles in an aqueous solution are considered another potential reaction medium for rapid hydrate formation (Takahata et al., 2010; Govindaraj et al., 2015; Yu et al., 2016, 2018). In case of severe sedimentation of hydrophobic particles in the reaction system, mechanical agitation is necessary during the hydrate formation. A carbon-based suspension is preferable to bulk materials in a fixed bed as the hydrate reaction system, since there are three distinct advantages when particles are dispersed in a liquid phase: the greater gas-liquid contact area of stirred suspensions, a more uniformly distributed hydrate crystallization process, and the feasibility of a continuous production process (Govindaraj et al., 2015).

By investigating methane hydrate formation kinetics in an activated carbon particle suspension at loadings of $0.5,1.0$, and $2.0 \mathrm{wt} \%$, Govindaraj et al. elucidated that suspensions with a higher fraction of activated carbon particles had stronger promotion effects on hydrate formation kinetics (Govindaraj et al., 2015). Meanwhile, a prominent positive correlation was established between the activated carbon concentration and the hydrate gas storage capacity, where the gas storage capacity was increased by $60 \%$ in a $2.0 \mathrm{wt} \%$ suspension compared to a pure water system. Although in several studies, the graphite had marginal promotion effects on methane hydrates, mixtures of graphite and other promoters, e.g., a mixture of graphite and hematite or a mixture of graphite and surfactant could lead to rapid hydrate formation (Takahata et al., 2010; Yu et al., 2016). Carbon nanotubes, in particular, attracted most interest for the excellent thermal properties reported in some literature. By adding multi-walled or single-walled carbon nanotubes to pure water, the gas consumption and hydrate reaction rate during hydrate formation were dramatically improved (Park et al., 2010). A comparative study on the enhanced formation of methane hydrate by different types of CNTs indicated that a shorter nucleation stage and more rapid growth process were obtained when short nanotubes (CM-95) rather CM-100 were applied as additives as a result of the larger specific area of the shorter MWCNTs (Kim et al., 2011).

In summary, carbon particle suspensions have obvious promotion effects on gas hydrate formation. The primary reason for this is the enlarged gas-liquid contact area provided by suspended particles, which leads to a mass transfer enhancement. However, it is noted that hydrate formation must be carried out with the aid of stirring, and it thus requires extra energy consumption and the use of an agitation apparatus.

\section{Gas Hydrate Formation With Carbon-Based Nanofluid}

Nanofluid is actually a stable dispersion formed by nanoparticles dispersed homogeneously in an aqueous phase. Nanofluid is considered an excellent hydrate reaction medium based on its superior mass transfer and heat transfer properties ( $\mathrm{Li}$ et al., 2017; Nashed et al., 2018). The behaviors of nanoparticles in nanofluid that promote hydrate formation are as follows. Firstly,

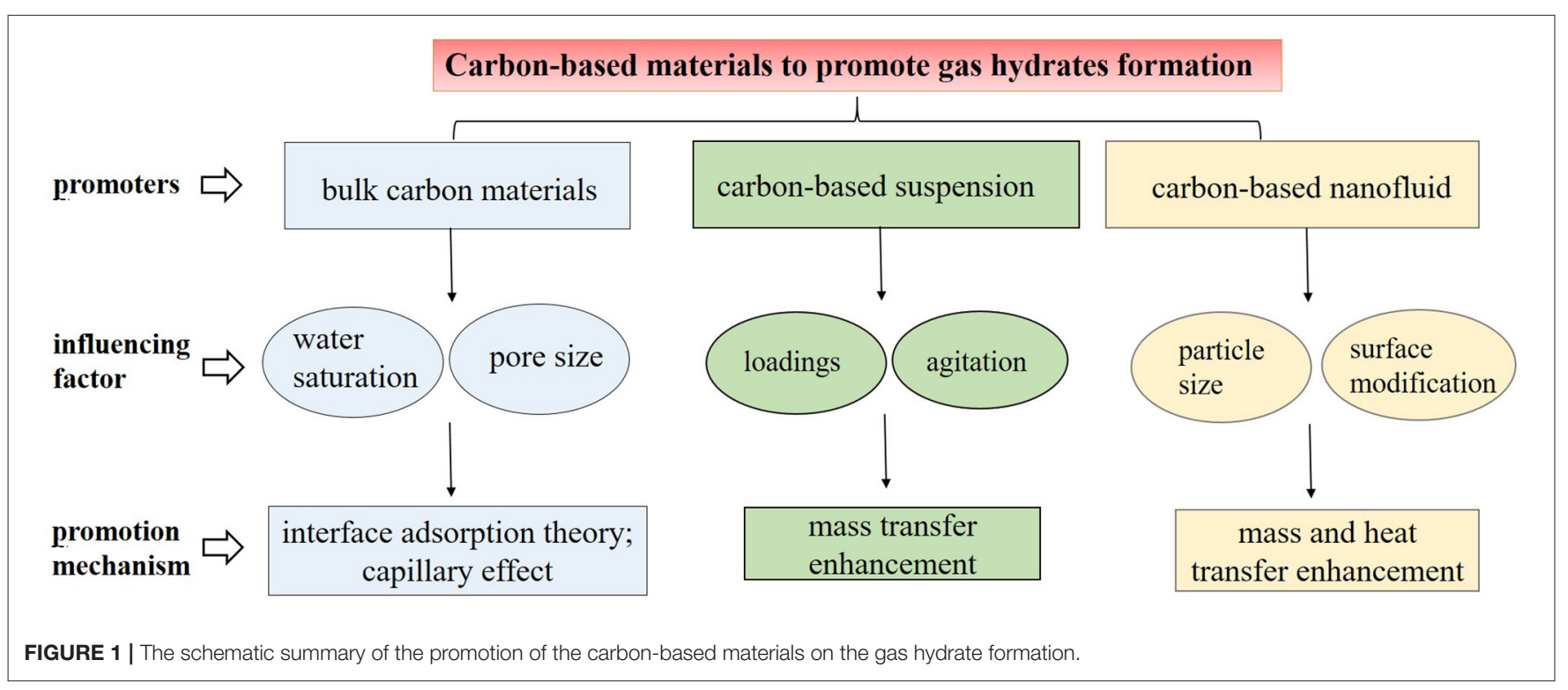


the nanoparticles move like microstirrers in the liquid through Brownian motion, resulting in constant updating of the gasliquid interface. Secondly, the nanoparticles have high specific surface areas and can thus offer plenty of nucleation sites for hydrate formation. Lastly, the continuous movement of carbon nanoparticles helps to remove the heat generated during hydrate formation. Carbon nanomaterials such as carbon nanotubes and graphene are more beneficial to heat transfer due to their intrinsic high thermal conductivity.

Nanofluid constituted by water-soluble carbon nanotubes has been verified to be an excellent promoter for gas hydrate formation (as listed in Table 1B). When an oxidized CNT nanofluid was used as the reaction system, the gas consumption was up to 4.5 times higher than in water (Park et al., 2012; Li et al., 2017). The promotion efficiency of chemically or physically treated CNT nanofluid exceeded that of pristine CNTs. For instance, acid-treated CNTs, SDS-coated CNTs and plasmafunctionalized CNTs could efficiently reduce induction time, increase gas consumption, and enhance growth rate (Park et al., 2010; Pasieka et al., 2013, 2015). The promotion efficiency of the CNT-based nanofluid, however, is affected by the particle fraction, the surface functional groups, and the treatment methods. The best concentration of OCNTs for promoting the growth of methane hydrate was $0.003 \%$ in Park et al. (2010). In view of the marked reactivity of the sulfonate groups contained in SDS, some researchers have coated the CNT surfaces with SDS, long-chain polymers containing $\mathrm{SO}_{3}$-, or Reactive Red 195 molecules and then dispersed the CNTs in water for use as the reaction system. Hydrates formed in these nanofluids all exhibited gas storage capacities that were elevated to $140-150$ $\mathrm{v} / \mathrm{v}$, and the hydrate reactions finished within $100 \mathrm{~min}$ (Song Y. et al., 2017; Song Y. M. et al., 2017; Song et al., 2019). Moreover, with the aid of a high-speed ball milling process, the obtained functionalized CNTs (such as RR195@CNTs) had excellent recycling performance in the hydrate formation process (Song et al., 2019). Due to the thermal conductivity of metal nanoparticles (nano-Ag or nano- $\mathrm{Cu}$ ), a prepared compound nanofluid containing OCNTs grafted by metal nanoparticles had a stronger promotion effect than the one-component nanofluid, with the exception that the metal nanoparticle-grafted OCNT nanofluid was not as stable as an OCNT nanofluid (Song et al., 2018).

Since graphene has smooth surfaces and is easy to functionalize by sulfonate groups or to load with metal nanoparticles, this two-dimensional carbon material is also introduced to hydrate formation reactions. Wang et al. (2017) grafted sulfonate groups successfully to graphene by covalent bonding and used it in methane hydrate formation. The results showed that the promotion efficiency of SGO (sulfated graphene) was better than that of GO (oxidized graphene). In another work, nano-Ag coated SGO was prepared for methane

\section{REFERENCES}

Aman, Z. M., and Koh, C. A. (2016). Interfacial phenomena in gas hydrate systems. Chem. Soc. Rev. 45, 1678-1690. doi: 10.1039/c5cs00791g hydrate formation, and a shorter hydrate formation stage was achieved compared to SGO (He and Wang, 2018).

Considering that the fraction of carbon nanoparticles in the nanofluid is far smaller, the promotion efficiency of the equivalent carbon-based material in nanofluid is superior to the materials in suspension or a packed bed. Besides, the stable carbon-based nanofluid has excellent recycling performance in repeated hydrate formation, which thus contributes to more economical hydrate production.

\section{CONCLUSION AND PROSPECTS}

This work is devoted to the summary of hydrate formation in various carbon media of different forms: porous carbon materials in packed beds, particles in suspension, and nanoparticles in nanofluid. Figure 1 highlights the themes of this mini review. Porous carbons provide a large interface area for gas-liquid contact, and particles in suspension or nanofluids are helpful for heat and mass transfer enhancement. To sum up, carbon-based materials, either in macro or micro forms, all show unique promotion effects on gas hydrate formation. Carbon-based nanofluid is the preferable medium among these for achieving economical and efficient hydrate production. Accordingly, it is necessary to develop more economical and efficient carbon-based nanofluids via surface modifications or coupling with other promoters. Besides, a majority of current research focuses on experimental investigation, while few works have attempted molecular illustration of the gas hydrates promoted by those carbon materials. Molecular simulation or mathematical modeling to investigate the hydrate formation characteristics and hydrate growth mechanism in carbon-based materials is therefore required, and this would also be helpful for designing and propelling the application of novel carbon materials for hydratebased technology.

\section{AUTHOR CONTRIBUTIONS}

Y-MS was in charge of literature collection, review, and writing. $\mathrm{R}-\mathrm{QL}$ contributed to the tools and the internet search. FW and D-BZ helped write the manuscript. J-HS and LY assisted with manuscript enhancement. All authors contributed to the article and approved the submitted version.

\section{FUNDING}

This work was supported financially by the National Natural Science Foundation of China under the grants 51676031, 51976087, 21706269, and 21978142 and by the Natural Science Foundation of Shandong Province with grant number ZR2018PEE004.
Andres-Garcia, E., Dikhtiarenkob, A., Fauthc, F., Silvestre-Alberod, J., Ramos-Fernándezd, E. V., Jorge, G., et al. (2019). Methane hydrates Nucleation in microporous materials. Chem. Eng. J. 360, 569-576. doi: 10.1016/j.cej.2018.11.216 
Babu, P., Yee, D., Linga, P., Palmer, A., Khoo, B. C., Tan, T. S., et al. (2013). Morphology of methane hydrate formation in porous media. Energ. Fuel. 27, 3364-3372. doi: 10.1021/ef4004818

Casco, M. E., Cuadrado-Collados, C., Martínez-Escandell, M., Rodríguez-Reinoso, F., and Silvestre-Albero, J. (2017). Influences of the oxygen-containing surface functional groups in the methan hydrate nucleation and growth in nanoporous carbon. Carbon 123, 299-301. doi: 10.1016/j.carbon.2017. 07.061

Celzard, A., and Marêché, J. F. (2006). Optimal wetting of active carbons for methane hydrate formation. Fuel 85, 957-966. doi: 10.1016/j.fuel.2005.10.019

Cuadrado-Collados, C., Farrando-Pérez, J., Martínez-Escandell, M., Missyul, A., and Silvestre-Albero, J. (2020). Effect of additives in the nucleation and growth of methane hydrates confined in a high-surface area activated carbon material. Chem. Eng. J. 338, 124-224. doi: 10.1016/j.cej.2020.124224

Cuadrado-Collados, C., Fauth, F., Such-Basanez, I., Martínez-Escandell, M., and Silvestre-Albero, J. (2018). Methane hydrate formation in the confined nanospace of activated carbons in seawater environment. Micropor. Mesopor. Mat. 255, 220-225. doi: 10.1016/j.micromeso.2017.07.047

Govindaraj, V., Mech, D., Pandey, G., Nagarajan, R., and Sangwai, J. S. (2015). Kinetics of methane hydrate formation in the presence of activated carbon and nano-silica suspensions in pure water. J. Nat. Gas Sci. Eng. 26, 810-818. doi: 10.1016/j.jngse.2015.07.011

He, Y., Sun, M.-T., Chen, C., Zhang, G.-D., Chao, K., Lin, Y., et al. (2019). Surfactant-based promotion to gas hydrate formation for energy storage. J. Mater. Chem. A 7, 21634-21661. doi: 10.1039/c9ta07071k

$\mathrm{He}$, Y., and Wang, F. (2018). Hydrate-based $\mathrm{CO}_{2}$ capture: kinetic improvement via graphene-carried -SO3- and Ag nanoparticles. J. Mater. Chem. A 6, 22619-22625. doi: 10.1039/C8TA08785G

Javanmardi, J., Nasrifar, K., Najibi, S. H., and Moshfeghian, M. (2005). Economic evaluation of natural gas hydrate as an alternative for natural gas transportation. Appl. Therm. Eng. 25, 1708-1723. doi: 10.1016/j.applthermaleng.2004.10.009

Kim, N. J., Park, S. S., Kim, H. T., and Chun, W. (2011). A comparative study on the enhanced formation of methane hydrate using CM95 and CM-100 MWCNTs. Int. Commun. Heat Mass 38, 31-36. doi: 10.1016/j.icheatmasstransfer.2010.10.002

Koh, C. A., Sloan, E. D., Sum, A. K., and Wu, D. T. (2011). Fundamentals and Applications of Gas Hydrates. Annu. Rev. Chem. Biomol. 22, 237-257. doi: 10.1146/annurev-chembioeng-061010-114152

Kumar, A., Bhattacharjee, G., Kulkarni, B. D., and Kumar, R. (2015). Role of Surfactants in Promoting Gas Hydrate Formation. Ind. Eng. Chem. Res. 54, 12217-12232. doi: 10.1021/acs.iecr.5b03476

Lee, J. D., Song, M., Susilo, R., and Englezos, P. (2006). Dynamics of methane-propane clathrate hydrate crystal growth from liquid water with or without the presence of n-heptane. gryst. Growth Des. 6, 1428-1439. doi: $10.1021 / \operatorname{cg} 0600647$

Li, D. L., Peng, H., and Liang, D. Q. (2017). Thermal conductivity enhancement of clathrate hydrate with nanoparticles. Int. J. Heat Mass Tran. 104, 566-573. doi: 10.1016/j.ijheatmasstransfer.2016.08.081

Lim, S. H., Riffat, S. B., Park, S. S., Oh, S.-J., Chun, W., and Kim, N.-J. (2014). Enhancement of methane hydrate formation using a mixture of tetrahydrofuran and oxidized multi-wall carbon nanotubes. Int. J. Energ. Res. 38, 374-379. doi: 10.1002/er.3051

Liu, H., Zhan, S., Guo, P., Fan, S., and Zhang, S. (2018). Understanding the characteristic of methane hydrate equilibrium in materials and its potential application. Chem. Eng. J. 349, 775-781. doi: 10.1016/j.cej.2018.05.150

Mingjun, Y., Yongchen, S., Liu, Y., Yongjun, C., and Qingping, L. (2010). Influence of pore size, salinity and gas composition upon the hydrate formation conditions. Therm. Chem. Eng. Data 18, 292-296. doi: 10.1016/S1004-9541(08)60355-9

Mohan, M., Sharma, V. K., Kumar, E. A., and Gayathri, V. (2019). Hydrogen storage in carbon materials-A review. Energy Storage 1:35. doi: 10.1002/est2.35

Najibi, H., Chapoy, A., and Tohidi, B. (2008). Methane_natural gas storage and delivered capacity for activated carbons in dry and wet conditions. Fuel 87, 7-13. doi: 10.1016/j.fuel.2007.03.044

Nashed, O., Partoon, B., Lal, B., Sabil, K. M., and Shariff, A. M. (2018). Review the impact of nanoparticles on the thermodynamics and kinetics of gas hydrate formation. J. Nat. Gas Sci. Eng. 55, 452-465. doi: 10.1016/j.jngse.2018.05.022
Nikitin, A., Li, X., Zhang, Z., Ogasawara, H., Dai, H., and Nilsson, A. (2008). Hydrogen storage in carbon nanotubes through the formation of stable C-H bonds. Nano Lett. 8, 162-167. doi: 10.1021/nl0 $72325 \mathrm{k}$

Palodkar, A. V., and Jana, A. K. (2020). Clathrate hydrate dynamics with synthetic and bio-surfactant in porous media: model formulation and validation. Chem. Eng. Sci. 213:115386. doi: 10.1016/j.ces.2019.115386

Park, S. S., An, E. J., Lee, S. B., Chun, W. G., and Kim, N. J. (2012). Characteristics of methane hydrate formation in carbon nanofluids. J. Ind. Eng. Chem. 18, 443-448. doi: 10.1016/j.jiec.2011.11.045

Park, S. S., Lee, S. B., and Kim, N. J. (2010). Effect of multi-walled carbon nanotubes on methane hydrate formation. J. Ind. Eng. Chem. 16, 551-555. doi: 10.1016/j.jiec.2010.03.023

Pasieka, J., Coulombe, S., and Servio, P. (2013). Investigating the effects of hydrophobic and hydrophilic multi-wall carbon nanotubes on methane hydrate growth kinetics. Chem. Eng. Sci. 104, 998-1002. doi: 10.1016/j.ces.2013. 10.037

Pasieka, J., Coulombe, S., and Servio, P. (2014). The effect of hydrophilic and hydrophobic multi-wall carbon nanotubes on methane dissolution rates in water at three phase equilibrium (V-L-w-H) conditions. Ind. Eng. Chem. Res. 53, 14519-14525. doi: 10.1021/ie502457c

Pasieka, J., Jorge, L., Coulombe, S., and Servio, P. (2015). Effects of as-produced and amine-functionalized multi-wall carbon nanotubes on carbon dioxide hydrate formation. Energ. Fuel. 29, 5259-5266. doi: 10.1021/acs.energyfuels.5b 01036

Perrin, A., Celzard, A., Marêch,é, J. F., and Furdin, G. (2003). Methane storage within dry and wet active carbons a comparative study. Energ. Fuel. 17, 1283-1291. doi: 10.1021/ef030067i

Siangsai, A., Rangsunvigit, P., Kitiyanan, B., Kulprathipanja, S., and Linga, P. (2015). Investigation on the roles of activated carbonparticle sizes on methane hydrate formation and dissociation. Chem. Eng. Sci. 126, 383-389. doi: 10.1016/j.ces.2014.12.047

Sloan, E. D. (1998). Clathrate Hydrate of Natural Gases. New York, NY: Marcel Dekker.

Song, Y., Wang, F., Liu, G. Q., Luo, S. J., and Guo, R.B. (2017). Promotion efffect of nanotubes-doped SDS on the methane hydrate formation. Energ.Fuel. 31, 1850-1857. doi: 10.1021/acs.energyfuels.6b02418

Song, Y. M., Wang, F., Guo, G., Luo, S. J., and Guo, R. B. (2017). Amphiphilic-polymer-coated carbon nanotubes as promoters for methane hydrate formation. ACS Sustain Chem Eng. 5, 9271-9278. doi: 10.1021/acssuschemeng.7b02239

Song, Y. M., Wang, F., Luo, S. J., Guo, R. B., and Xu, D. (2019). Methane hydrate formation improved by water-soluble carbon nanotubes via $\pi-\pi$ conjugated molecules functionalization. Fuel 243, 185-191. doi: 10.1016/j.fuel.2019.01.081

Song, Y. M., Wang, F., Guo, G., Luo, S.-J., and Guo, R.-B. (2018) Energy-efficient storage of methane in the formed hydrates with metal nanoparticles-grafted carbon nanotubes as promoter. Appl. Energ. 224, 175-183. doi: 10.1016/j.apenergy.2018.04.068

Takahata, M., Kashiwaya, Y., and Ishi, K. (2010). Kinetics of methane hydrate formation catalyzed by iron oxide and carbon under intense stirring conditions. Mater Trans 51, 727-734. doi: 10.2320/matertrans.M2 009369

Thomas, S. (2003). Review of ways to transport natural gas energy from countries which do not need the gas for domestic use. Energy 28, 1461-1477. doi: 10.1016/s0360-5442(03)00124-5

Veluswamy, H. P., Kumar, A., Seo, Y., Lee, J. D., and Linga, P. (2018). A review of solidified natural gas (SNG) technology for gas storage via clathrate hydrates. Appl. Energ. 216, 262-285. doi: 10.1016/j.apenergy.2018.02.059

Wang, F., Meng, H. L., Guo, G., Luo, S. J., and Guo, R. B. (2017). Methane hydrate formation promoted by -SO3-coated graphene oxide nanosheets. ACS sustain. Chem. Eng. 5, 6597-6604. doi: 10.1021/acssuschemeng.7b00846

Wang, R., Liu, T., Ning, F., Ou, W., Zhang, L., Wang, Z., et al. (2019). Effect of hydrophilic silica nanoparticles on hydrate formation: insight from the experimental study. J. Energ Chem. 30, 90-100. doi: 10.1016/j.jechem.2018.02.021

Yan, L., Chen, G., Pang, W., and Liu, J. (2005). Experimental and modeling study on hydrate formation in wet activated carbon. J. Phys. Chem. B 109, 6025-6030. doi: $10.1021 /$ jp045679y 
Yang, M., Song, Y., Ruan, X., Liu, Y., Zhao, J., and Li, Q. (2012). Thermodynamic modeling of pure components including the effects of capillarity. Energies 5, 925-937. doi: 10.3390/en5040925

Yu, Y. S., Xu, C. G., and Li, X. S. (2018). Evaluation of $\mathrm{CO}_{2}$ hydrate formation from mixture of graphite nanoparticle and sodium dodecyl benzene sulfonate. J. Ind. Eng. Chem. 59, 64-69. doi: 10.1016/j.jiec.2017.10.007

Yu, Y. S., Zhou, S. D., Li, X. S., and Wang, S. L. (2016). Effect of graphite nanoparticles on $\mathrm{CO}_{2}$ hydrate phase equilibrium. Fluid Phase Equilibr. 414, 23-28. doi: 10.1016/j.fluid.2015.12.054

Zhang, Z., Liu, Z., Pan, Z., Baena-Morenoe, F. M., and Soltanian, M. R. (2020). Effect of porous media and its distribution on methane hydrate formation in the presence of surfactant. Appl. Energ. 261:114373. doi: 10.1016/j.apenergy.2019.114373

Zhong, Y., and Rogers, R. E. (2000). Surfactant effects on gas hydrate formation. Chem. Eng. Sci. 55, 4175-4187. doi: 10.1016/S0009-2509(00)00072-5
Zhou, L., and Sun, Y. (2001). Enhancement of the methane storage on activated carbon by preadsorbed water. AIChE J. 48, 2412-2416. doi: 10.1002/aic.690481030

Conflict of Interest: The authors declare that the research was conducted in the absence of any commercial or financial relationships that could be construed as a potential conflict of interest.

Copyright (C) 2020 Song, Liang, Wang, Shi, Zhang and Yang. This is an open-access article distributed under the terms of the Creative Commons Attribution License (CC $B Y)$. The use, distribution or reproduction in other forums is permitted, provided the original author(s) and the copyright owner(s) are credited and that the original publication in this journal is cited, in accordance with accepted academic practice. No use, distribution or reproduction is permitted which does not comply with these terms. 